\title{
Measured CPAP in a Noninvasive Pediatric Airway and Lung Model
}

\author{
Neil D Fernandes, Esther Chung, Michael D Salt, Beverly Ejiofor, Ryan W Carroll, \\ and Robert M Kacmarek
}

\begin{abstract}
BACKGROUND: Bronchiolitis is the most common cause of admission in children $<2$ y of age in the United States. The standard of care involves supportive measures, including noninvasive interventions such as CPAP. CPAP is traditionally delivered through a full face mask; however, pediatric ICUs have been exploring the use of the RAM cannula by Neotech as a mode of CPAP delivery. The level of CPAP delivered via the RAM cannula is uncertain. We performed an in vitro study to determine the level of CPAP delivered via the RAM cannula utilizing a pediatric lung model. METHODS: Models of 7 sizes of pediatric upper airways, produced with a 3-dimensional printer, were connected to a breathing simulator. We applied each size of RAM cannula to weight-appropriate airway and lung compliance parameters, delivering pressures of 5,7 , and $10 \mathrm{~cm}$ $\mathrm{H}_{2} \mathrm{O}$ using a ventilator in the CPAP mode. Leaks of $0 \%, 20 \%, 40 \%$, and $60 \%$ were generated to emulate a complete seal, a poor fit, and open-mouth breathing. The outcome measure was the difference in CPAP, referred to as "\%leak effect," measured by the lung simulator relative to the CPAP set

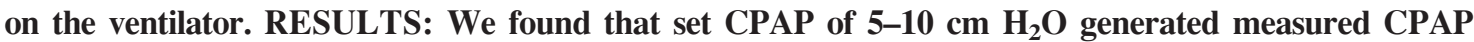
ranging from 2.6 to $9.7 \mathrm{~cm} \mathrm{H}_{2} \mathrm{O}$. For the set CPAP levels of 5, 7, and $10 \mathrm{~cm} \mathrm{H}_{2} \mathrm{O}$, the mean \%leak effect values of measured CPAP from the set CPAP were $-25 \%,-26 \%$, and $-25.7 \%$, respectively. For each specific cannula-airway combination, increasing the set pressure and decreasing the air leak resulted in higher levels of CPAP delivered. CONCLUSIONS: The RAM cannula delivered varying amounts of CPAP, with a percent loss of approximately $-25 \%$ depending on the level of leak in the system. With minimal leak, it is conceivable that the RAM cannula can be used to deliver clinically meaningful CPAP. Key words: noninvasive ventilation; CPAP; PEEP; child; pediatric intensive care units; RAM cannula. [Respir Care 2021;66(1):87-94. (C) 2021 Daedalus Enterprises]
\end{abstract}

\section{Introduction}

Bronchiolitis is the inflammation of the small airways of the lungs, and it is predominantly caused by a viral illness, usually affecting infants and children age $<2$ y. It is a frequent cause of emergency department visits and hospitalization among infants. ${ }^{1-3}$ Within the first year of life, $10 \%$ of

Dr Fernandes, Ms Chung, Dr Salt, Ms Ejiofor, Dr Carroll, and Dr Kacmarek are affiliated with the Massachusetts General Hospital, Boston, Massachusetts. Dr Fernandes, Dr Salt, Dr Carroll, and Dr Kacmarek are affiliated with Harvard Medical School, Boston, Massachusetts. Drs Fernandes, Salt, and Carroll are affiliated with the Division of Pediatric Critical Care, Department of Pediatrics, Massachusetts General Hospital for Children, Boston, Massachusetts.

Dr Kacmarek has disclosed relationships with Medtronic, Orange Medical, and Nihon Kohdon. All other authors have disclosed no conflicts of interest. children are diagnosed with bronchiolitis. ${ }^{4}$ This illness is usually a mild, self-limiting disease, but $2-5 \%$ of children require hospitalization ${ }^{5-10}$ and $1-2.7 \%$ require critical care support. ${ }^{11,12}$ The standard management of bronchiolitis involves supportive care such as ensuring adequate fluid intake, antipyretics, and humidified oxygen supplementation if hypoxia is present. ${ }^{13}$ However, due to dynamic narrowing of the peripheral airways on expiration exacerbated by inflammation, a recent Cochrane Review suggested that CPAP may help keep inflamed airways open, thereby increasing the functional residual capacity throughout the respiratory cycle. ${ }^{14-16}$

Correspondence: Neil D Fernandes MD, Massachusetts General Hospital, 55 Fruit St, Bigelow 6, Boston, MA 02114. E-mail: ndfernandes@ mgh.harvard.edu.

DOI: 10.4187/respcare.07864 
CPAP may be given noninvasively to infants using nasal prongs, a nasopharyngeal tube, an infant nasal mask, or a face mask. CPAP is administered using a commercially available circuit in conjunction with a continuous flow source or with a ventilator. A nextgeneration nasal cannula (RAM cannula, Neotech, Valencia, California) is currently being used as an interface to provide noninvasive ventilatory support, such as nasal intermittent positive-pressure ventilation, CPAP, and noninvasive neurally-adjusted ventilatory assist. ${ }^{17}$ There is currently a dearth of information in the pediatric population on the amount of CPAP delivered through the RAM cannula. We believe it is of paramount importance for providers and clinicians to know the relationship between set and delivered pressures to better serve our patients. To help bridge this knowledge gap, we designed this study to quantify the effect of the RAM cannula system on airway pressures in various simulated, spontaneously breathing, pediatric lung models with different leak conditions at a range of pressures typically used for the pediatric population. We hypothesized that the measured CPAP level would increase with increasing set CPAP and decrease as the system leak increased.

\section{Methods}

\section{Experimental Setup and Apparatus}

A Servo-i ventilator (Maquet, Wayne, New Jersey) was used in conjunction with the ASL 5000 Breathing Simulator 3.5 (IngMar Medical, Pittsburgh, Pennsylvania) to evaluate the delivery of CPAP across 7 RAM cannula sizes (N4900-N4906). The ventilator was connected to the lung model using age- and size-appropriate standard corrugated tubing (Neonatal and Pediatric Breathing Circuit, Hudson RCI-Teleflex, Morrisville, North Carolina) (Table 1, Fig. 1, and Fig. 2). This study was conducted at Massachusetts General Hospital, Boston, Massachusetts.

\section{QUICK LOOK}

\section{Current knowledge}

The RAM cannula has become an option for delivering CPAP in pediatrics, but the delivered level of CPAP is uncertain. To our knowledge, no publication describes the CPAP delivered by the full array of RAM cannulas, and therefore the literatures excludes several key pediatric ages/sizes.

\section{What this paper contributes to our knowledge}

The RAM cannula delivered varying amounts of CPAP, with a \%leak effect of approximately $-25 \%$, depending on the level of leak in the system. Increasing set CPAP and decreasing leaks resulted in greater levels of measured CPAP. With minimal leak, it is conceivable that the RAM cannula could be used to deliver clinically meaningful CPAP.

\section{Lung Model Settings}

The ASL 5000 was programmed to simulate 7 patient models with different lung mechanics based on weights of $0.5,1,2,4,8,15$, and $20 \mathrm{~kg}$ to correlate with the RAM cannula sizes tested. The lung models were based on normally compliant lungs to simulate a healthy individual. Previous bench studies, clinical studies, and pre-set lung models from the ASL 5000 lung simulator were used to determine the various respiratory settings for each model. ${ }^{18-27}$ Table 2 summarizes each model setting.

\section{RAM Cannula Specifications and Upper Airway Model}

Seven sizes of Neotech RAM cannulas were evaluated: N4900, N4901, N4902, N4903, N4904, N4905, and N4906. The upper airway model was developed based on the work of Sivieri et al. ${ }^{26}$ The amount of turbulence generated by the turbinates and bends in the airway will differ between every

Table 1. Setup and Models

\begin{tabular}{lcclcl}
\hline \hline $\begin{array}{c}\text { Weight } \\
\text { Model, kg }\end{array}$ & $\begin{array}{c}\text { Endotracheal } \\
\text { Tube Size }\end{array}$ & $\begin{array}{c}\text { Diameter of Nasal } \\
\text { Model, mm }\end{array}$ & Cannula (Color) & $\begin{array}{c}\text { Circuit } \\
\text { Type }\end{array}$ & Servo-i Setting \\
\hline 0.5 & 5 & 3 & N4900 (white) & Neonatal & Infant, NIV-Nasal CPAP \\
1 & 5.5 & 3 & N4901 (green) & Neonatal & Infant, NIV-Nasal CPAP \\
2 & 6 & 4 & N4902 (blue) & Neonatal & Infant, NIV-Nasal CPAP \\
4 & 6.5 & 5 & N4903 (orange) & Neonatal & Infant, NIV-Nasal CPAP \\
8 & 7 & 6 & N4904 (yellow) & Neonatal & Infant, NIV-Nasal CPAP \\
10 & 8 & 7 & N4905 (mint) & Pediatric & Adult, NIV-Pressure Control \\
20 & 9 & 7 & N4906 (purple) & Pediatric & Adult, NIV-Pressure Control
\end{tabular}

$\overline{\mathrm{NIV}}=$ noninvasive ventilation 


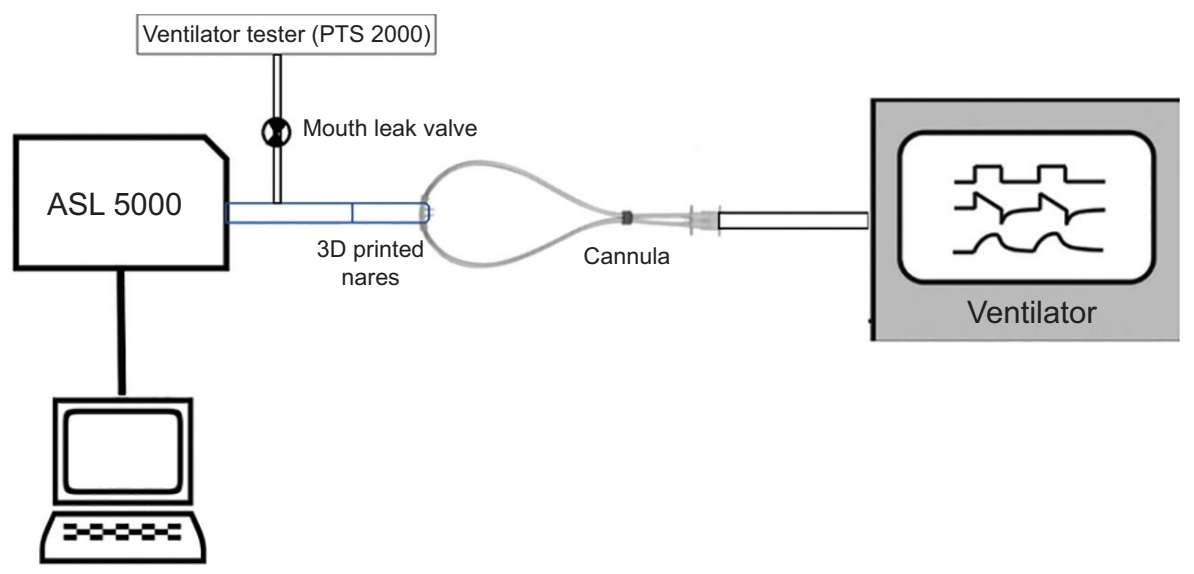

Fig. 1. Model setup.

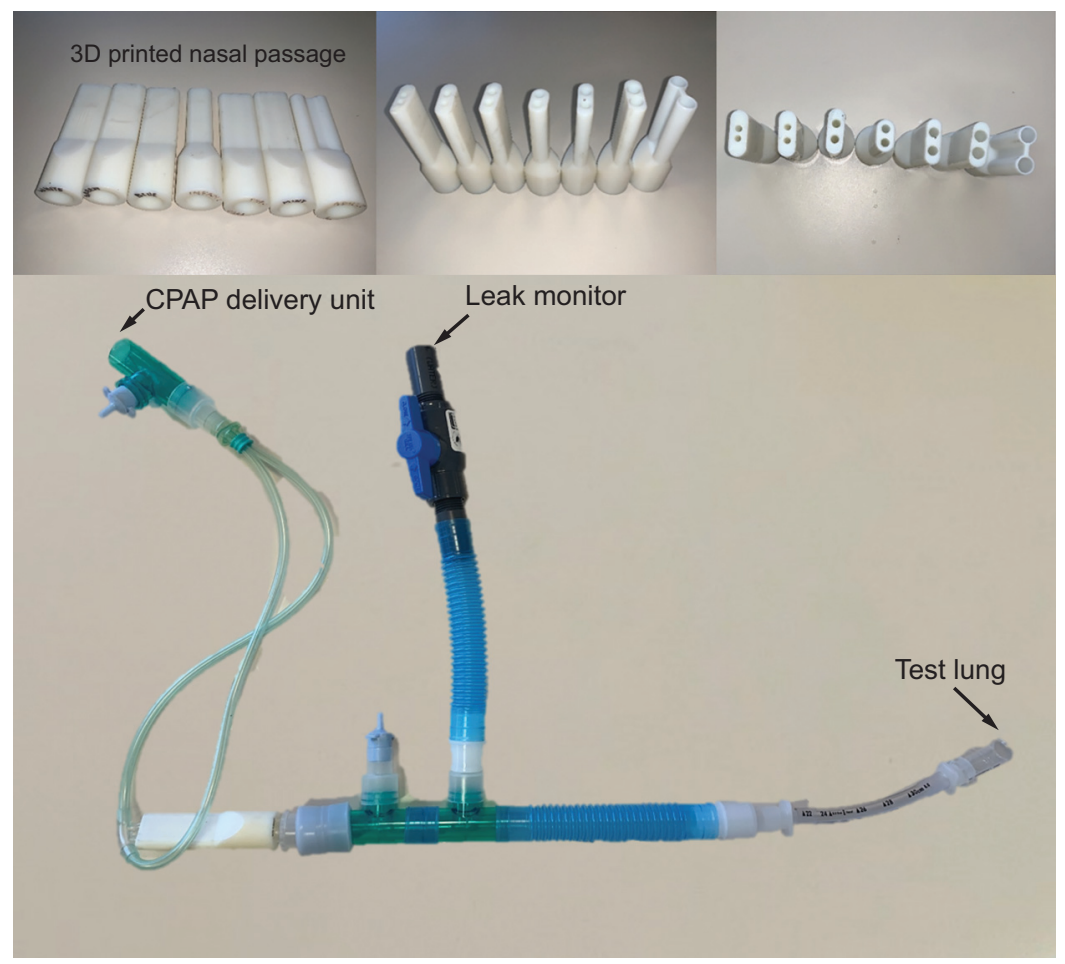

Fig. 2. Individual model components.

single patient due to varied anatomy, therefore these variables were circumvented using this predicate model. ${ }^{26,28,29}$ The external diameter of each RAM cannula prong at its base attachment to the delivery tubing was measured with a digital caliper (Mitutoyo, Aurora, Illinois) with a resolution of $0.1 \mathrm{~mm}$. Measurements were made with air flow going through the cannulas to ensure accurate estimation of the cannulas' diameter during use. This measurement was made with the manufacturer's recommended flow moving through the cannulas: $2.5 \mathrm{~L} / \mathrm{min}$ for sizes N4900-N4903, and 15 L/min for sizes N4904-N4906.
A simulated upper airway was developed from corrugated tubing, and a simulated nasal passageway was created with a 3-dimensional printer (Fig. 1). The diameter of the nasal passageway was approximately $1 \mathrm{~mm}$ wider than the size of the RAM cannula prongs at their base attachment to the delivery tubing, resulting in a perfect, occlusive fit in each cannula-model pair. The nasal passageway was $5.0 \mathrm{~cm}$ in length and was connected to a simulated trachea, which was then connected to the port of endotracheal tubes of various sizes depending on the lung model (Fig. 1 and Table 1). A T-shaped connector and 
Measured CPAP in a Pediatric Model

Table 2. Lung Model Body Weight Settings

\begin{tabular}{|c|c|c|c|c|c|c|c|}
\hline & \multicolumn{7}{|c|}{ Weight Model, kg } \\
\hline & 0.5 & 1 & 2 & 4 & 8 & 10 & 20 \\
\hline Compliance, $\mathrm{mL} / \mathrm{cm} \mathrm{H}_{2} \mathrm{O}$ & 0.5 & 1 & 2 & 5 & 5 & 10 & 15 \\
\hline $\mathrm{P}_{0.1}, \mathrm{~cm} \mathrm{H}_{2} \mathrm{O}$ & -2.1 & -2.8 & -3.5 & -4.2 & -4 & -4 & -4 \\
\hline Tidal volume, $\mathrm{mL} / \mathrm{kg}$ & 0.9 & 3.2 & 7.8 & 23.2 & 42 & 60 & 90 \\
\hline Resistance, $\mathrm{cm} \mathrm{H}_{2} \mathrm{O} / \mathrm{L} / \mathrm{s}$ & 200 & 150 & 100 & 50 & 35 & 30 & 20 \\
\hline Inspiratory time, s & 0.25 & 0.30 & 0.35 & 0.40 & 0.50 & 0.50 & 0.70 \\
\hline Breathing frequency, breaths/min & 70 & 60 & 50 & 40 & 35 & 30 & 30 \\
\hline Increase, $\%$ & 24.2 & 20 & 17 & 13.5 & 14.5 & 14.5 & 14.5 \\
\hline Hold, \% & 5 & 10 & 12.2 & 13.2 & 12 & 12 & 12 \\
\hline Release, \% & 19.5 & 20 & 19.5 & 17.8 & 17 & 17 & 17 \\
\hline Pause, $\%$ & 0 & 0 & 0 & 0 & 0 & 0 & 0 \\
\hline
\end{tabular}

valve were inserted between the endotracheal tube fitting and the trachea to create leak percentages of $0 \%, 20 \%$, $40 \%$, and $60 \%$. The leak percentages were utilized to simulate CPAP delivery via RAM cannula when there is no leak (ie, closed mouth and tight-fitting nasal prongs: $0 \%$ leak) and when a child breaths with an open mouth or there is a leak around the prongs (ie, various leak contributions of $20 \%, 40 \%$, and $60 \%$ ). Leak flow and percentage of total system flow were determined with a PTS 2000 ventilator tester (Puritan-Bennett Mallinckrodt, Carlsbad, California). To set the leak percentages, the Servo-i was set to the desired CPAP level and $100 \%$ of the flow from the ventilator ran through the PTS 2000. The $0 \%, 20 \%, 40 \%$, and $60 \%$ leaks were mathematically calculated from the liters of flow per minute that were registered at $100 \%$ leak at the specific CPAP level. The endotracheal tube was then attached to the ASL 5000.

\section{CPAP Delivery System and Ventilator Settings}

The Servo-i ventilator was connected to a Siemens air compressor (Siemens, Lancaster, Pennsylvania) for both air and oxygen. The Servo-i ventilator was used in noninvasive ventilation mode for all sizes of the RAM cannula. For sizes N4900-N4904, the ventilator was on the infant, nasal CPAP mode, and the neonatal breathing circuit was used. The customizable settings for the infant, nasal CPAP mode were as follows: oxygen concentration: 21\%; PEEP: 5, 7, or $10 \mathrm{~cm} \mathrm{H}_{2} \mathrm{O}$ depending on the trial. For sizes N4905 and N4906, the ventilator was on adult, pressure control mode, and the pediatric breathing circuit was used. The customizable settings for the adult, pressure control mode were as follows: oxygen concentration: 21\%; pressure control above PEEP: 0; PEEP: 5, 7, or 10 $\mathrm{cm} \mathrm{H}_{2} \mathrm{O}$ depending on the trial; breathing frequency: 15 breaths/min; inspiratory time: $0.9 \mathrm{~s}$; $\mathrm{T}$ inspiratory rise:
0.2 s. Apnea backup ventilation for this mode was activated and set at $40 \mathrm{~s}$.

\section{Protocol}

The specific pressures measured within the CPAP delivery system during each trial were alveolar pressure (peak inspiratory pressure, peak expiratory pressure, and end-expiratory pressure). Each cannula and lung model pairing were evaluated with different leak and CPAP settings. Each configuration was tested once. After establishment of the specific CPAP and leak in each model, pressures were recorded for $3 \mathrm{~min}$. Pressure data were collected at $200 \mathrm{~Hz}$, recorded on computers, and saved for analysis. Data from the acquisition module and the ventilator tester were time-synchronized with the ASL 5000. Measurement of peak, minimum and mean pressures were determined from 10 breaths after 3 min of running the simulator during each recording period.

\section{Statistical Analysis}

Alveolar pressure data were collected using the IngMar Medical ASL 5000 software (IngMar Medical). Results are expressed as mean $\pm \mathrm{SD}$ values unless otherwise stated. A Pearson correlation and multiple linear regression model were run to assess the relationship between set CPAP, leak, cannula size, and measured CPAP. Measured CPAP was determined with a $99.9 \% \mathrm{CI}$, and statistical significance was set at $P<.001$. We also measured an outcome variable, referred to as "\%leak effect," which reflects the difference in set CPAP from the measured CPAP based on the amount of leak in the system. This difference was calculated as \%leak effect $=[($ measured CPAP - set CPAP $) /$ set $\mathrm{CPAP}] \times 100$. Thus, negative values indicate that the measured CPAP was less than the set CPAP. Statistical 
Table 3. Mean Measured CPAP at Various Leak and Set CPAP Levels

\begin{tabular}{|c|c|c|c|c|}
\hline \multirow{2}{*}{ Cannula (Color) } & \multirow{2}{*}{ Leak, $\%$} & \multicolumn{3}{|c|}{$\mathrm{CPAP}, \mathrm{cm} \mathrm{H}_{2} \mathrm{O}$} \\
\hline & & 5 & 7 & 10 \\
\hline \multirow[t]{4}{*}{ N4900 (white) } & 0 & 3.85 & 5.35 & 7.62 \\
\hline & 20 & 3.18 & 4.67 & 6.6 \\
\hline & 40 & 2.48 & 3.58 & 4.94 \\
\hline & 60 & 1.7 & 2.36 & 3.18 \\
\hline \multirow[t]{4}{*}{ N4901 (green) } & 0 & 5.06 & 7.13 & 10.12 \\
\hline & 20 & 4.56 & 6.44 & 9.28 \\
\hline & 40 & 3.82 & 3.85 & 7.89 \\
\hline & 60 & 2.77 & 2.77 & 5.34 \\
\hline \multirow[t]{4}{*}{ N4902 (blue) } & 0 & 3.76 & 5.26 & 7.51 \\
\hline & 20 & 3.04 & 5.27 & 5.98 \\
\hline & 40 & 2.3 & 4.07 & 4.37 \\
\hline & 60 & 1.44 & 1.91 & 3.43 \\
\hline \multirow[t]{4}{*}{ N4903 (orange) } & 0 & 3.8 & 5.4 & 7.8 \\
\hline & 20 & 3.2 & 4.62 & 6.4 \\
\hline & 40 & 2.58 & 3.58 & 5.16 \\
\hline & 60 & 1.77 & 2.48 & 3.48 \\
\hline \multirow[t]{4}{*}{ N4904 (yellow) } & 0 & 4.9 & 6.9 & 9.95 \\
\hline & 20 & 4.45 & 6.33 & 8.97 \\
\hline & 40 & 3.65 & 5.26 & 7.61 \\
\hline & 60 & 2.68 & 3.97 & 5.64 \\
\hline \multirow[t]{4}{*}{ N4905 (mint) } & 0 & 5.48 & 7.53 & 11.62 \\
\hline & 20 & 5.29 & 7.17 & 10.39 \\
\hline & 40 & 4.85 & 6.29 & 9.35 \\
\hline & 60 & 4.34 & 5.31 & 7.3 \\
\hline \multirow[t]{4}{*}{ N4906 (purple) } & 0 & 5.6 & 8.16 & 11.09 \\
\hline & 20 & 5.6 & 7.52 & 10.49 \\
\hline & 40 & 4.91 & 6.68 & 9.03 \\
\hline & 60 & 3.88 & 5.12 & 7.46 \\
\hline
\end{tabular}

analysis was conducted using SPSS 24.0 (IBM, Armonk, New York).

\section{Results}

There was an overall increase in the measured CPAP as the set CPAP increased and as the leak decreased. The mean measured CPAP across various leaks and cannula sizes $($ no. $=84)$ are depicted in Table 3 . We noted the highest measured CPAP in the larger RAM cannulas (N4905 [mint] and N4906 [purple]) and the lowest measured CPAP in the smaller RAM cannula (N4902 [blue] and N4900 [white]). Figure 3 illustrates the mean measured CPAP when keeping the cannula size and set CPAP constant, while varying the leak. Figure 4 represents the mean measured CPAP when keeping the leak and set CPAP constant, while varying the cannula size.

A Pearson correlation was run to assess the relationship between set CPAP, leak, RAM cannula, and measured CPAP. There was a statistically significant, strong positive correlation between set CPAP and measured CPAP of
$r(80)=0.641(P<.001)$; a moderate positive correlation between cannula size and measured CPAP of $r(80)=0.41$ $(P<.001)$; and a moderate negative correlation between leak and measured CPAP of $r(80)=-0.5(P<.001)$.

A multiple linear regression model was calculated to understand the effect of set CPAP and leak on measured CPAP. We noted a significant regression outcome of $F$ $(2,81)=76.969(P<.001)$ with an $R^{2}$ of 0.647 . The predicted "measured" CPAP is equal to $1.615+[(0.737) \times$ Set CPAP $]+[(-0.052) \times$ Leak $]$, where CPAP is measured in $\mathrm{cm} \mathrm{H}_{2} \mathrm{O}$ and leak is measured in \%. Both set CPAP and leak were significant predictors of measured CPAP.

Lastly, we averaged all the measured CPAP and RAM cannula sizes and calculated the "\% leak effect" for set CPAP of 5, 7, and $10 \mathrm{~cm} \mathrm{H}_{2} \mathrm{O}$ as $-25 \%,-26 \%$, and $-25.7 \%$, respectively.

\section{Discussion}

In this simulation-based experiment, we evaluated the use of the Neotech RAM cannula to deliver CPAP. To our knowledge, this is the first in vitro study of the RAM cannula attached to a ventilator with the intention of supplying CPAP across varying leak percentages, in varying sizes of pediatric lung models, utilizing the full spectrum of RAM cannula sizes. Most importantly, our in vitro study indicates that the pressure delivered is regulated and prevented from exceeding the set level by $>1-2 \mathrm{~cm} \mathrm{H}_{2} \mathrm{O}$. There were 3 primary findings in our study: (1) increased leak resulted in decreased measured CPAP; (2) increased set CPAP resulted in increased measured CPAP; (3) larger cannula sizes resulted in increased measured CPAP with a set CPAP. Our results show that transmission of pressure across the nasal interface is dependent on the amount of leak, across the interface or open mouth, with good pressure transmission when the nasal cannula is properly sized using a template as recommended by the manufacturer.

Iyer and Chatburn ${ }^{30}$ conducted a neonatal lung-based model study using the RAM cannula and reported a loss of 25-37\% from the set pressure. Their model was based on nasal cannula and nostril size. However, the study did not state the amount of leak that was present in the circuit, which our study aimed to overcome. Another in vitro study using RAM cannula showed a loss of $60 \%$ of the pressure from the set CPAP. ${ }^{31}$ This study tested a wide variety of settings in addition to different nare sizes and open-mouth models used in the neonatal population. An in vivo study investigating delivered pressures using the RAM cannula in preterm infants and showed a loss of $40-50 \%$ of the set CPAP. ${ }^{32}$ Our study differs from these previous studies in a couple of ways. We studied the full array of RAM cannula sizes and commensurate pressures commonly used across the pediatric population. We also aimed to overcome deficits in the prior studies by using a wide range of leaks to 


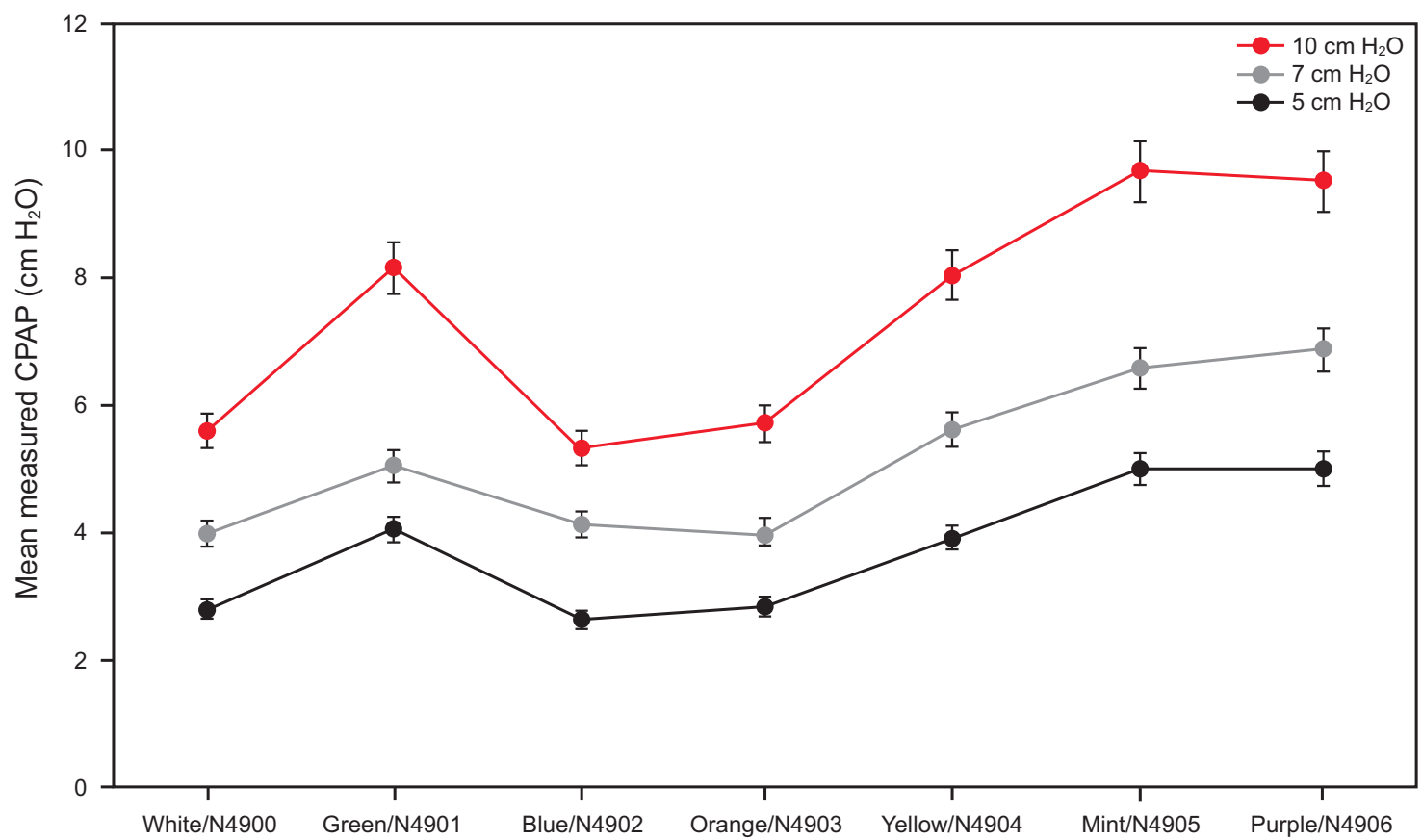

Fig. 3. Measured CPAP for set cannula size, set CPAP, and varying leak (mean \pm SD). Flows were $2.5 \mathrm{~L} / \mathrm{min}$ for sizes N4900-N4903, and $15 \mathrm{~L} / \mathrm{min}$ for sizes N4904-N4906.

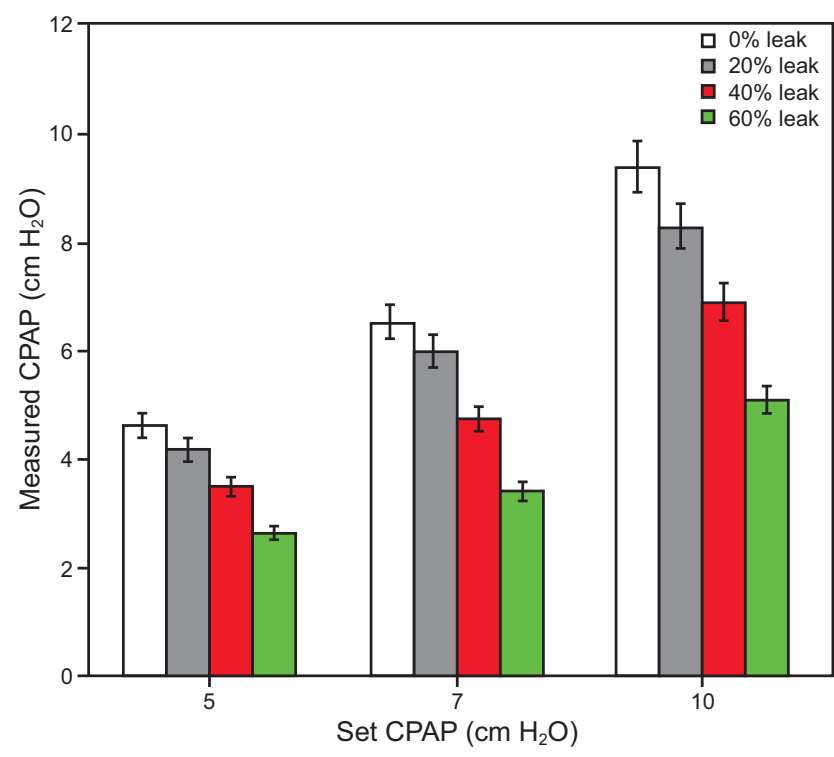

Fig. 4. Set CPAP versus measured CPAP (mean \pm SD). Data are averaged for all cannula sizes and set CPAP.

simulate a patient with an open mouth or crying versus closed mouth. The intent was to simulate real-world situations so that these data could be more fully translated to the bedside. We found that when the CPAP was averaged over the entire array of cannula sizes, the loss of CPAP with a $0 \%$ leak was $6-7 \%$, and for those pressures delivered with $20 \%$ leak the loss was $14-17 \%$. In other words, with a leak of $0 \%$, simulating a closed mouth complete seal scenario, we measured CPAP of 93-94\%, and for leaks of $20 \%$, which simulates an $80 \%$ occlusion best-fit scenario, we delivered $83-86 \%$ of set CPAP. Armed with these data points, a care provider may feel more secure in the level of CPAP being delivered to the alveoli using the RAM cannula and may confidently adjust the ventilator settings to accommodate the level of leak determined at the bedside.

As mentioned earlier, we did note an increasing trend in the measured CPAP as the cannula size increased. We hypothesize that leaks in general have a lesser effect on the CPAP delivered because the larger cannula requires greater flow and, in our experience, fits the child better. However, we did notice that the N4901 (green) cannula did not follow the normal trajectory of pressure increase seen with the other cannulas (Fig. 3). The experiment was repeated multiple times with similar results. We speculate that this could be due to the increased pressure passing through a small cannula dimension.

The RAM cannula is easy to use and to keep in place, like a high-flow nasal cannula (HFNC), which may have better tolerability when compared to a full face/oronasal mask for CPAP. ${ }^{33-35}$ The RAM cannula has the advantages of not completely occluding the child's face as occurs with a full face/oronasal CPAP mask, causing anxiety and further distress in children. This may be the reason sedation is often used (ie, to help the child tolerate the mask), an intervention that, by itself, poses significant risk and complications. ${ }^{36}$ The HFNC interface is similarly easy to apply, but some critics have concerns with its use due to the unknown 


\section{Measured CPAP in a Pediatric Model}

amount of pressure provided with a high flow. ${ }^{37-39}$ The RAM cannula may help bridge this gap by combining the ease of use and tolerability of HFNC with the reliability of using a full face mask or an oronasal mask for CPAP, while incurring little to none of the disadvantages. Anecdotally, we have observed a trend in our unit, as well as with our transportation teams, toward broad adoption of the RAM cannula, presumably due to the ease of use. In our personal experience, we have seen that it is clinically more tolerable to a full face/oronasal mask, and with minimal loss of the set CPAP, as shown in our study, we anticipate that it could be used as an alternative to HFNC or full face/oronasal mask CPAP for some children coming to the ICU in need of an escalation in respiratory support and ICU care.

The primary limitation of this study is that it was not performed in pediatric patients, but in models that simulated pediatric airways. However, we believe that the essential mechanics of the pediatric respiratory system are well represented by this model. The relationship between set CPAP and the pressure delivered to the lungs in an actual clinical situation depends on many uncontrollable factors, which is why noninvasive ventilation in general (including noninvasive ventilation through nasal prongs), is an exercise in rough estimates at best. Although the anatomy of our lung model does not exactly resemble the airway anatomy of the pediatric patient, our intent was not to duplicate the pediatric upper airway anatomy and the way variable anatomy may affect delivered CPAP, but rather to evaluate the effect of leaks on the level of CPAP delivered using the RAM cannula. We assumed that the size of the leak would mimic what we see clinically despite the differences in anatomy. The leak compensation options on the PB840 and Servo-i ventilators are designed to compensate for leaks in the breathing circuit to maintain CPAP and prevent auto-triggering during noninvasive and invasive ventilation. It is possible that not using leak compensation for this experiment or using a different ventilator that does not offer leak compensation may have yielded different results. Further study of this issue is warranted.

\section{Conclusions}

The use of the RAM cannula to deliver CPAP to pediatric patients may be safe and efficacious. As with CPAP delivered with a full face/oronasal mask, CPAP delivery with the RAM cannula takes advantage of all the ventilator safeguards utilized in CPAP mode. Most importantly, pressure is regulated and prevented from exceeding the set level by $>1-2 \mathrm{~cm} \mathrm{H}_{2} \mathrm{O}$, and the mean \%leak effect averaged approximately $-25 \%$ across all models of RAM cannula and set CPAP levels of 5, 7, and $10 \mathrm{~cm} \mathrm{H}_{2} \mathrm{O}$. We observed that measured CPAP was negatively affected by leak and positively affected by higher set CPAP and RAM cannula size, respectively.

\section{ACKNOWLEDGMENTS}

We thank Dr Hui Zheng from the MGH Biostatistics Center for reviewing the statistical methodology and data.

\section{REFERENCES}

1. Hasegawa K, Tsugawa Y, Brown DF, Mansbach JM, Camargo CA, Jr. Temporal trends in emergency department visits for bronchiolitis in the United States, 2006 to 2010. Pediatr Infect Dis J 2014;33(1):11-18.

2. Praznik A, Vinšek N, Prodan A, Erçulj V, Pokorn M, Mrviç T, et al. Risk factors for bronchiolitis severity: a retrospective review of patients admitted to the university hospital from central region of Slovenia. Influenza Other Respi Viruses 2018;12(6):765-771.

3. Rivera-Sepulveda A, Garcia-Rivera EJ. Epidemiology of bronchiolitis: a description of emergency department visits and hospitalizations in Puerto Rico, 2010-2014. Trop Med Health 2017;45:24.

4. Ducharme FM. Management of acute bronchiolitis. BMJ 2011;342: d1658.

5. Deshpande SA, Northern V. The clinical and health economic burden of respiratory syncytial virus disease among children under 2 years of age in a defined geographical area. Arch Dis Child 2003;88(12):10651069.

6. Henderson FW, Collier AM, Clyde WA Jr, Denny FW. Respiratorysyncytial-virus infections, reinfections and immunity: a prospective, longitudinal study in young children. N Engl J Med 1979;300(10): 530-534.

7. Murray J, Bottle A, Sharland M, Modi N, Aylin P, Majeed A, et al. Risk factors for hospital admission with RSV bronchiolitis in England: a population-based birth cohort study. PLoS One 2014;9(2):e89186.

8. Nagakumar P, Doull I. Current therapy for bronchiolitis. Arch Dis Child 2012;97(9):827-830.

9. Stockman LJ, Curns AT, Anderson LJ, Fischer-Langley G. Respiratory syncytial virus-associated hospitalizations among infants and young children in the United States, 1997-2006. Pediatr Infect Dis J 2012;31(1):5-9.

10. Zorc JJ, Hall CB. Bronchiolitis: recent evidence on diagnosis and management. Pediatrics 2010;125(2):342-349.

11. Lebel MH, Gauthier M, Lacroix J, Rousseau E, Buithieu M. Respiratory failure and mechanical ventilation in severe bronchiolitis. Arch Dis Child 1989;64(10):1431-1437.

12. Mansbach JM, Piedra PA, Stevenson MD, Sullivan AF, Forgey TF, Clark S, et al. Prospective multicenter study of children with bronchiolitis requiring mechanical ventilation. Pediatrics 2012;130(3):e492e500.

13. Davison C, Ventre KM, Luchetti M, Randolph AG. Efficacy of interventions for bronchiolitis in critically ill infants: a systematic review and meta-analysis. Pediatr Crit Care Med 2004;5(5):482-489.

14. Bont L. Current concepts of the pathogenesis of RSV bronchiolitis. Adv Exp Med Biol 2009;634:31-40.

15. Gupta S, Donn SM. Continuous positive airway pressure: physiology and comparison of devices. Semin Fetal Neonatal Med 2016;21(3): 204-211.

16. Jat KR, Mathew JL. Continuous positive airway pressure (CPAP) for acute bronchiolitis in children. Cochrane Database Syst Rev 2019;1: CD010473.

17. Nzegwu NI, Mack T, DellaVentura R, Dunphy L, Koval N, Levit O, et al. Systematic use of the ram nasal cannula in the Yale-New Haven Children's Hospital neonatal intensive care unit: a quality improvement project. J Matern Fetal Neonatal Med 2015;28(6):718-721. 


\section{Measured CPAP in a Pediatric Model}

18. Breatnach E, Abbott GC, Fraser RG. Dimensions of the normal human trachea. AJR Am J Roentgenol 1984;142(5):903-906.

19. Dullenkopf A, Kretschmar O, Knirsch W, Tomaske M, Hug M, Stutz $\mathrm{K}$, et al. Comparison of tracheal tube cuff diameters with internal transverse diameters of the trachea in children. Acta Anaesthesiol Scand 2006;50(2):201-205.

20. Gerhardt T, Hehre D, Feller R, Reifenberg L, Bancalari E. Pulmonary mechanics in normal infants and young children during first 5 years of life. Pediatr Pulmonol 1987;3(5):309-316.

21. Griscom NT, Wohl ME. Dimensions of the growing trachea related to age and gender. AJR Am J Roentgenol 1986;146(2):233-237.

22. Itagaki T, Bennett DJ, Chenelle CT, Fisher DF, Kacmarek RM. Performance of leak compensation in all-age ICU ventilators during volume-targeted neonatal ventilation: a lung model study. Respir Care 2017;62(1):10-21.

23. Itagaki T, Chenelle CT, Bennett DJ, Fisher DF, Kacmarek RM. Effects of leak compensation on patient-ventilator synchrony during premature/neonatal invasive and noninvasive ventilation: a lung model study. Respir Care 2017;62(1):22-33.

24. Likus W, Bajor G, Gruszczyńska K, Baron J, Markowski J. Nasal region dimensions in children: a CT study and clinical implications. Biomed Res Int 2014;2014:125810.

25. Phelan PD, Williams HE. Ventilatory studies in healthy infants. Pediatr Res 1969;3(5):425-432.

26. Sivieri EM, Gerdes JS, Abbasi S. Effect of HFNC flow rate, cannula size, and nares diameter on generated airway pressures: an in vitro study. Pediatr Pulmonol 2013;48(5):506-514.

27. Rusconi F, Castagneto M, Gagliardi L, Leo G, Pellegatta A, Porta N. Reference values for respiratory rate in the first 3 years of life. Pediatrics 1994;94(3):350-355.

28. Ejiofor BD, Carroll RW, Bortcosh W, Kacmarek RM. PEEP generated by high-flow nasal cannula in a pediatric model. Respir Care 2019;64 (10):1240-1249.
29. Nielsen KR, Ellington LE, Gray AJ, Stanberry LI, Smith LS, DiBlasi RM. Effect of high-flow nasal cannula on expiratory pressure and ventilation in infant, pediatric, and adult models. Respir Care 2018;63 (2): $147-157$

30. Iyer NP, Chatburn R. Evaluation of a nasal cannula in noninvasive ventilation using a lung simulator. Respir Care 2015;60(4):508-512.

31. Gerdes JS, Sivieri EM, Abbasi S. Factors influencing delivered mean airway pressure during nasal CPAP with the RAM cannula. Pediatr Pulmonol 2016;51(1):60-69.

32. Singh N, McNally MJ, Darnall RA. Does the RAM cannula provide continuous positive airway pressure as effectively as the hudson prongs in preterm neonates? Am J Perinatol 2019;36(8):849-854.

33. Lee JH, Rehder KJ, Williford L, Cheifetz IM, Turner DA. Use of high flow nasal cannula in critically ill infants, children, and adults: a critical review of the literature. Intensive Care Med 2013;39(2):247-257.

34. Ramnarayan P, Schibler A. Glass half empty or half full? The story of high-flow nasal cannula therapy in critically ill children. Intensive Care Med 2017;43(2):246-249.

35. Spentzas T, Minarik M, Patters AB, Vinson B, Stidham G. Children with respiratory distress treated with high-flow nasal cannula. J Intensive Care Med 2009;24(5):323-328.

36. Matsumoto T, Tomii K, Tachikawa R, Otsuka K, Nagata K, Otsuka K, et al. Role of sedation for agitated patients undergoing noninvasive ventilation: clinical practice in a tertiary referral hospital. BMC Pulm Med 2015;15:71.

37. Hoffman SB, Terrell N, Driscoll CH, Davis NL. Impact of high-flow nasal cannula use on neonatal respiratory support patterns and length of stay. Respir Care 2016;61(10):1299-1304.

38. Locke RG, Wolfson MR, Shaffer TH, Rubenstein SD, Greenspan JS. Inadvertent administration of positive end-distending pressure during nasal cannula flow. Pediatrics 1993;91(1):135-138.

39. Manley BJ, Dold SK, Davis PG, Roehr CC. High-flow nasal cannulae for respiratory support of preterm infants: a review of the evidence. Neonatology 2012;102(4):300-308. 